The Organizing Committee wishes to acknowledge the following companies whose support has made this meeting possible:

\title{
Major Sponsors
}

Amgen Deutschland GmbH

Rhône-Poulenc Rorer GmbH

\section{Exhibitors and Contributors}

Abbott GmbH
Baxter Deutschland GmbH
Bayer AG
Becton Dickinson GmbH
Berlin Chemie AG
Biotest Pharma GmbH
Boehringer Ingelheim Bioproducts
Boehringer Mannheim GmbH
Bristol-Myers Squibb GmbH
CellPro Deutschland GmbH
CellSystems Biotechnologie Vertrieb
Centeon Pharma GmbH
DAKO Diagnotika GmbH
Deutsche Leukämiehilfe e.V.
DPC Biermann GmbH
Essex Pharma GmbH
Fresenius AG
Genzyme Diagnostics

GlaxoWellcome GmbH \& Co. Hamburgische Elektrizitäts Werke AG Invitrogen BV

Janssen-Cilag GmbH

S. Karger AG

Lederle Arzneimittel GmbH

Leiras Oy

Lilly Deutschland GmbH

Miltenyi Biotec GmbH

New York Medical College

NeXstar Pharmaceuticals GmbH

Pfizer $\mathrm{GmbH}$

PharMingen Deutschland GmbH

Schering Plough Int.

Sequus Pharmaceuticals Inc.

SmithKline Beecham Pharma GmbH

Tsumura \& Co.

Vysis GmbH

The Organizing Committee gratefully acknowledges the patience and support, including editorial assistance, in the preparation of this conference of Joyce Eshet, Symposium Secretary, and the patience of Dr. J.-L. da Silva, Symposium Coordinator. Special thanks go to Mrs. Eileen Jenks for her superb administrative and technical assistance. 